\title{
Alterações físico-químicas e movimentação de íons em Latossolo gibbsítico sob doses de gesso
}

\author{
Milson Evaldo Serafim ( $\left.{ }^{1 *}\right)$; José Maria de Lima ( $\left.{ }^{2}\right)$; Vico Mendes Pereira Lima ( ${ }^{3}$ ); \\ Walmes Marques Zeviani ( $\left.{ }^{4}\right)$; Patrícia Terezinha Pessoni $\left({ }^{5}\right)$ \\ (') Instituto Federal de Educação, Ciência e Tecnologia de Mato Grosso, Cáceres (MT), Brasil. \\ (2) Universidade Federal de Lavras, Departamento de Ciência do Solo, Caixa Postal 3037, 37200-000 Lavras (MG), Brasil. \\ (3) Instituto Federal de Educação, Ciência e Tecnologia do Norte de Minas, 39900-000 Almenara (MG), Brasil. \\ (4) Universidade Federal do Paraná, Departamento de Estatística, 81531-990 Curitiba (PR), Brasil. \\ (5) Instituto Agronômico (IAC), Programa de Pós-Graduação, Caixa Postal 28, 13020-902 Campinas (SP), Brasil. \\ (*) Autor correspondente: milson.serafim@cas.ifmt.edu.br
}

Recebido: 13/dez./2010; Aceito: 5/set./2011

\begin{abstract}
Resumo
Com o objetivo de avaliar o efeito de doses de gesso no ponto de carga zero estimado (PCZ), na dinâmica do cálcio, magnésio, potássio e sulfato, e na retenção de água de um Latossolo Vermelho distroférrico gibbsítico, textura muito argilosa, realizou-se experimento em vasos, em casa de vegetação. Foram estudadas seis doses de gesso agrícola (correspondentes a 0, 3, 6, 9, 12 e $15 \mathrm{Mg} \mathrm{ha}^{-1}$ ) e duas condições de fornecimento de água, "sem veranico" e "com veranico" para a soja cultivada. Na coleta de solo para o experimento foram consideradas as camadas 0-0,2 m e 0,7-0,9 m representando os horizontes A e Bw respectivamente. Foram montados vasos com a sobreposição de dois tubos de PVC de 0,2 m de comprimento e 0,1 m de diâmetro interno, formando duas camadas: a superior, com material do horizonte A, corrigido com calcário dolomítico, e a inferior, com material do horizonte Bw, sem correção do pH; ambas na densidade de $1 \mathrm{~kg} \mathrm{dm}^{-3}$. O PCZ foi alterado em função das doses de gesso. Houve aumento dos teores de Ca, também em resposta as doses de gesso. Não houve diferença nos teores de $\mathbf{S}$ na camada superficial, mas houve aumento na camada subsuperficial em resposta à dose de gesso. Constatou-se redução nos teores de Mg na camada superficial e elevação na camada subsuperficial, com o aumento das doses de gesso. Não houve variação nos teores de K e na retenção de água para as diferentes doses de gesso e regime de fornecimento de água.
\end{abstract}

Palavras-chave: PCZ; lixiviação; fertilidade do solo, correção de solo, retenção de água.

\section{Physico-chemical attributes and ion leaching in a Gibbsitic Latosol as affected by gypsum}

\section{Abstract}

The effect of gypsum on the point of zero charge-PZC, calcium, magnesium, potassium and sulfate dynamics, and water retention were evaluated in a very clayey dystrophic gibbsitic Red Latosol. Six doses of gypsum (corresponding to 0, 3, 6, 9, 12 and $15 \mathrm{Mg} \mathrm{ha}^{-1}$ ) and two water supply conditions (with and without water deficit) were imposed to soybean crop. Soil was sampled at the depths of 0-0.2 $\mathrm{m}$ and 0.7-0.9 m, representing the A and Bw horizons, respectively. Soil samples were placed in PVC tubes (0.2 $\mathrm{m}$ in length and $0.1 \mathrm{~m}$ of diameter), simulating two layers: the upper layer had $\mathrm{A}$ horizon soil, which was amended with dolomitic limestone; and the bottom layer had Bw horizon soil, under the natural pH. Both layers had soil density of $1 \mathrm{~kg} \mathrm{dm}^{-3}$. The PZC was changed by gypsum; as gypsum dose increased, calcium concentration increased in both soil layers. There was no difference in S value in the upper layer due to gypsum; however it increased in the subsurface layer as gypsum was applied. Lower Mg concentration was found in the upper layer, whereas increases in Mg were noticed in the bottom layer as gypsum doses increased. No changes in water retention and $\mathrm{K}$ concentration were found in response to gypsum and water supply regimes.

Key words: PZC; leaching, soil fertility, soil correction, water retention. 


\section{INTRODUÇÃO}

$\mathrm{O}$ gesso agrícola $\left(\mathrm{CaSO}_{4} \cdot 2 \mathrm{H}_{2} \mathrm{O}\right)$ aplicado ao solo é fonte de cálcio e enxofre às plantas e, também, um corretivo do alumínio tóxico em profundidade. Estas características, associadas à elevada solubilidade e mobilidade do íon sulfato permitem que o gesso, quando aplicado na superfície do solo, seja solubilizado pela água das chuvas e, ou irrigação, sendo parte redistribuída para o subsolo (FARIA et al., 2003), potencializando, assim, o uso do gesso, por facilitar a correçáo do alumínio e elevar os teores de cálcio das camadas subsuperficiais de solos com esta limitação. Em solos como deste estudo, Latossolo gibbsítico, manejados com sistema conservacionista, o fornecimento de cálcio e correção do $\mathrm{Al}^{3+}$ no perfil pela aplicação de calcário em superfície pode ser limitado, sendo uma alternativa o gesso aplicado sozinho ou combinado com o calcário (CAires et al., 2003).

A presença de $\mathrm{Al}$ e a deficiência de cálcio estão entre os principais fatores que inibem o crescimento radicular, principalmente em Latossolos (Oliveira et al., 2009). Estes autores destacam a importância de práticas que favoreçam o enraizamento profundo das plantas cultivadas em solo da Região dos Cerrados, como forma de minimizar os efeitos dos frequentes veranicos sobre a produção das culturas.

O uso do gesso de forma desordenada, sem a observaçẫo de critérios físico-químicos, como o balanço de cargas, equilíbrio iônico e CTC, pode resultar em uma intensa movimentação de nutrientes, especialmente de potássio e magnésio (CAIres et al., 2003). O carreamento de íons no perfil pode ser benéfico, por estimular maior crescimento radicular, o que propicia maior absorção de nutrientes em profundidade. A calagem adequada do solo reduz o potencial de lixiviação de nutrientes do gesso, devido ao fornecimento de magnésio e aumento da capacidade de troca de cátions - CTC, aumentando a adsorção do potássio (CAires et al., 2004).

Os efeitos do gesso agrícola na floculação das partículas do solo refletem em melhoria na sua agregação (FAvaretto et al., 2006). Quando aplicado na superfície do solo, aumenta a concentraçáo de eletrólitos da água pluvial que infiltra no solo. Essa solução de solo mais concentrada comprime a dupla camada elétrica, fornece cálcio no complexo de troca (Dontsova e Norton, 2002) e favorece a agregação do solo. Existe também, o potencial do gesso aumentar a infiltraçáo e reduzir o escoamento superficial, por diminuir a impermeabilizaçáo da superfície e a formação crostas (FAVARETTo et al., 2006). Estes efeitos contribuem para o aumento da capacidade de retenção de água do solo (Beutler et al., 2002).

O gesso vem sendo utilizado há algumas décadas para correção de alumínio tóxico e elevação de teores de cálcio em camadas mais profundas do solo (ZAMBrosi et al., 2007), com recomendaçóes baseadas no teor de argila do solo, cujas doses são inferiores a $4 \mathrm{t} \mathrm{ha}^{-1}$. Atualmente, há grande tendência de utilizar doses elevadas de gesso em algumas culturas, com respostas positivas, mas ainda merece estudos, devido aos efeitos adversos mencionados anteriormente. Neste contexto, observa-se uma defasagem entre as tabelas oficiais de recomendação de gesso e as doses ótimas para as culturas. O efeito em alguns parâmetros do solo representa efeito também na produção das culturas, assim, o objetivo deste trabalho foi avaliar a influência de doses de gesso no ponto de carga zero (PCZ), na dinâmica do cálcio, magnésio, potássio, sulfato e na retenção de água do solo.

\section{MATERIAL E MÉTODOS}

O experimento foi realizado em casa de vegetação, em Lavras (MG), utilizando vasos. Foi utilizado material dos horizontes $\mathrm{A}$ e $\mathrm{Bw}$, amostrados nas camadas de 0-0,2 e 0,7-0,9 m, respectivamente, de um Latossolo Vermelho (10R 4/8) distroférrico $\left(\mathrm{V}=20,1 \% ; \mathrm{Fe}_{2} \mathrm{O}_{3}=220 \mathrm{~g} \mathrm{~kg}^{-1}\right)$ gibbsítico $(\mathrm{Ki}=0,96 ; \mathrm{Kr}=0,68)$ com $538 \mathrm{~g} \mathrm{~kg}^{-1} \mathrm{de}$ gibbsita, textura muito argilosa (LVdf) (ЕмBrapa, 2006) e intensamente lixiviado, em área com vegetação nativa; as características químicas e físicas são apresentadas na tabela 1, determinadas conforme EMBRAPA (1997).

O material coletado foi seco ao ar, passado em peneira de $4 \mathrm{~mm}$ e parte do material referente ao horizonte A foi incubado com calcário dolomítico por um período de 2 meses, para se elevar a saturação por bases a $60 \%$.

$\mathrm{O}$ experimento foi instalado em esquema fatorial $6 \times 2$, inteiramente casualizado, com quatro repetiçôes. Os tratamentos constaram do cultivo de soja (Glycine max L. Merrill cultivar Monsoy 8001) sob seis doses de gesso agrícola (equivalentes a 0, 3, 6, 9, 12 e $15 \mathrm{Mg} \mathrm{ha}^{-1}$ ) aplicadas sobre a superfície do solo, duas condiçôes de fornecimento de água: sem veranico (entre 6 e $80 \mathrm{kPa}$ ) e com veranico simulado.

Os vasos foram constituídos pela sobreposição de dois tubos de PVC, com $20 \mathrm{~cm}$ de altura de $10 \mathrm{~cm}$ de diâmetro interno; o tubo inferior recebeu solo do horizonte $\mathrm{Bw}$, sem correção do $\mathrm{pH}$, e o superior solo do horizonte $\mathrm{A}$, corrigido com calcário dolomítico, ambas as camadas ficaram com densidade de $1 \mathrm{~kg} \mathrm{dm}^{-3}$. A adubação dos vasos foi feita na superfície, segundo recomendação para o cultivo da soja em casa de vegetação, de acordo com Novais (1991).

Aos 16 dias após a emergência das plantas, foi dado início ao primeiro veranico simulado, por um período de sete dias. Uma semana depois, deu-se início ao segundo veranico simulado, tendo duração de cinco dias. O experimento foi encerrado aos 62 dias. As colunas de solo foram seccionadas na sua junção (A e B), obtendo-se assim a porção de $0-20 \mathrm{~cm}$ e $20-40 \mathrm{~cm}$, referentes às amostras dos horizontes $\mathrm{A}$ e $\mathrm{Bw}$ respectivamente. Foram retiradas 
amostras de solo de cada tratamento, nas duas camadas, para a realização de análises químicas e físicas.

Foram determinados os teores de $\mathrm{K}, \mathrm{Ca}, \mathrm{Mg}$ e $\mathrm{S}$, conforme EMBrapa (1997). O PCZ foi estimado para os tratamentos sem veranico, por meio da equação PCZ = $2 \mathrm{pH} \mathrm{KCl}-\mathrm{pH} \mathrm{H}_{2} \mathrm{O}$, conforme descrito por Coringa e WEBER (2008).

As curvas de retenção de água do solo foram obtidas para os 24 tratamentos, a partir de amostras deformadas, coletadas no momento em que as colunas foram desmontadas, destorroadas e passadas em peneira de $4 \mathrm{~mm}$.

Para as determinaçóes dos conteúdos de água nos potenciais aplicados, as amostras foram acondicionadas em anéis de PVC de $25 \mathrm{~mm}$ de diâmetro e $30 \mathrm{~mm}$ de altura, preparados com um tecido preso por borracha para compor o fundo do anel. As amostras foram saturadas por capilaridade, por meio de elevação gradual de uma lâmina de água em bandeja. Depois de saturadas, as amostras foram pesadas e submetidas aos seguintes potenciais: $-0,001,-0,002,-0,004,-0,006,-0,01 \mathrm{MPa}$, na mesa de tensão, e -0,033, -0,066, -0,3 e -1,5 MPa, nos aparelhos extratores de Richards, segundo EMBRAPA (1997). Após atingir o equilíbrio hídrico em cada potencial, as amostras foram pesadas e submetidas ao potencial subsequente, constituindo método por secamento. Após o ultimo potencial, as amostras foram secas em estufa a $\pm 105^{\circ} \mathrm{C}$, por 24 horas, para determinação do conteúdo de água do solo $(\theta)$.

$\mathrm{O}$ ajuste das curvas foi dado pelo conteúdo volumétrico de água $(\theta)$ em função da tensão da água no solo (h), empregando-se o modelo proposto por VAN GENUCHTEN (1980), utilizando o software SWRC (Dourado Neto et al., 2000), conforme equação 1:

$$
\theta=\left(\theta_{\text {sat }}-\theta_{\text {res }}\right)\left[1+(\theta h)^{\mathrm{n}}\right]^{-\mathrm{m}}+\theta_{\text {res }}
$$

sendo $\mathrm{h}$, a tensão da água no solo $(\mathrm{kPa}) ; \theta$ o conteúdo de água $\left(\mathrm{m}^{3} \mathrm{~m}^{-3}\right) ; \theta_{\text {sat }}$ o conteúdo de água na saturação $\left(\mathrm{m}^{3} \mathrm{~m}^{-3}\right) ; \theta_{\text {res }}$ o conteúdo de água no ponto de murcha permanente $\left(\mathrm{m}^{3} \mathrm{~m}^{-3}\right) ; \mathrm{m}$, n e $\theta$ os parâmetros de ajuste do modelo.

Os dados para as demais variáveis foram submetidos à análise de variância e, quando significativo, foram ajustados a modelos de regressão para doses de gesso; foram também aplicados testes de média, em função dos fatores qualitativos, utilizando o software estatístico R (RDCT, 2009).

\section{RESULTADOS E DISCUSSÃO}

$\mathrm{O}$ efeito de dose de gesso foi significativo sobre os valores do PCZ somente na condição sem veranico (Tabela 2). No caso do $\mathrm{Ca}$ e o $\mathrm{Mg}$, houve interação dupla em relação à camada $(\mathrm{C})$ e as doses $(\mathrm{D})$ e em relação à condição de umidade (U) e a camada (C); no caso do potássio $(\mathrm{K})$, houve interação apenas para U x C. Já para o sulfato $\left(\mathrm{SO}_{4}^{2-}\right)$ a interação foi significativa para $\mathrm{C} \times \mathrm{D}$ (Tabela 3).

$\mathrm{Na}$ condição sem gesso (controle), o valor do PCZ na camada A foi inferior ao da camada B, como pode ser observado pelos interceptos das equaçóes (Tabela 4); esse fato se deve à maior quantidade de matéria orgânica no material dessa camada (A) (Tabela 1), pois a matéria orgânica, isoladamente, possui baixo valor de PCZ e contribui para redução do PCZ médio das partículas do solo (FonTes et al., 2001). Na camada B, com menor teor de matéria orgânica, as propriedades eletroquímicas dos colóides minerais se sobressaem; predominam entre esses colóides, os óxi-hidróxidos de ferro e alumínio que possuem valores de PCZ acima de 8,0 (Fontes et al., 2001).

Para a camada superficial, houve um aumento nos valores de PCZ mediante as doses crescentes de gesso (Figura 1). Os valores de PCZ do solo podem aumentar ou diminuir com a adição de sulfato. McBride (1978) propóe a coprecipitaçáo de cátions divalentes com formas amorfas de alumínio precipitado, cujo composto atuaria como um íon determinante de potencial, aumentando cargas positivas e, consequentemente, o PCZ do solo estimado, considerando-se a diferença entre $\mathrm{pH}$ em solução de $\mathrm{KCl}$ e em água. Nesse método, a elevação da força iônica por parte das doses crescentes de gesso, induz a menores valores de "pH em água" (RAIJ, 1973). Esse efeito é menor no $\mathrm{pH}$ determinado em solução de $\mathrm{KCl}$ onde a força iônica já é elevada e o acréscimo desta pela elevação da dose de gesso é menos representativo. Esse processo é tão mais pronunciado quanto maior a quantidade de carga líquida negativa nas partículas do solo, expresso pela CTC efetiva ( $\mathrm{t}$ ), como ocorre na camada A (Tabela 1), em razão da maior quantidade de matéria orgânica.

$\mathrm{Na}$ camada B, houve um decréscimo do PCZ, em razão das doses crescentes de gesso (Figura 1). Além do menor efeito de força iônica descrito acima para a camada A, a presença do sulfato contribuiu para essa redução. Nessa camada, com a menor quantidade de matéria orgânica, as cargas positivas de óxidos de ferro e alumínio contribuem para diminuir a quantidade de carga líquida negativa;

Tabela 1. Análises químicas e físicas de amostras de solo (Latossolo Vermelho distroférrico gibbsítico) no momento da coleta do material

\begin{tabular}{|c|c|c|c|c|c|c|c|c|c|c|c|c|c|c|c|}
\hline Horiz. & $\mathrm{pH}$ & $\mathbf{P}$ & $\mathbf{K}$ & $\mathrm{Ca}$ & Mg & Al & $H+A l$ & SB & $\begin{array}{c}\text { ctc } \\
\text { efetiva }\end{array}$ & $\mathbf{T}$ & v & MO & P-rem & $\mathbf{S}$ & Argila \\
\hline & $\mathrm{H}_{2} \mathrm{O}$ & \multicolumn{2}{|c|}{$\left(\mathrm{mg} \mathrm{dm}^{-3}\right)$} & \multicolumn{7}{|c|}{$\left(\mathrm{cmol}_{\mathrm{c}} \mathrm{dm}^{-3}\right)$} & (\%) & $\left(\mathrm{g} \mathrm{kg}^{-1}\right)$ & $\left(\mathrm{mg} \mathrm{L}^{-1}\right)$ & $\left(\mathrm{mg} \mathrm{dm}^{-3}\right)$ & $\left(\mathbf{g ~ k g}^{-1}\right)$ \\
\hline$A$ & 5,6 & 24,2 & 11 & 3,2 & 0,4 & 0,1 & 5,6 & 3,6 & 3,7 & 9,2 & 39,3 & 32 & 16 & 123,8 & 730 \\
\hline B & 5,4 & 0,4 & 5 & 0,2 & 0,1 & 0,0 & 1,9 & 0,3 & 0,4 & 2,1 & 20,1 & 5 & - & 2,5 & 744 \\
\hline
\end{tabular}


Tabela 2. Resumo da análise de variância (Quadrados médios) para os valores de PCZ na condição sem veranico, para as camadas A e B

\begin{tabular}{|cl|}
\hline FV & PCZ \\
\hline Camada (C) & $1,30^{*}$ \\
\hline Dose (D) & $0,05^{\text {ns }}$ \\
\hline C x D & $0,22^{*}$ \\
\hline Resíduo & 0,02 \\
\hline
\end{tabular}

'Significativo pelo teste F a 5\% de probabilidade.

Tabela 3. Resumo da análise de variância (Quadrados médios) para os teores dos nutrientes estudados

\begin{tabular}{lcccc} 
FV & $\mathbf{K}$ & $\mathbf{C a}$ & $\mathbf{M g}$ & $\mathbf{S}$ \\
\hline Umidade (U) & $5,04^{\text {ns }}$ & $0,04^{*}$ & $0,38^{\text {ns }}$ & $490,06^{\text {ns }}$ \\
\hline Camada (C) & $486,00^{*}$ & $56,12^{*}$ & $0,67^{*}$ & $9,07^{\text {ns }}$ \\
\hline Dose (D) & $9,68^{\text {ns }}$ & $13,43^{*}$ & $0,37^{*}$ & $13911,55^{*}$ \\
U x C & $126,04^{*}$ & $21,66^{*}$ & $0,67^{*}$ & $135,14^{\text {ns }}$ \\
\hline U x D & $4,27^{\text {ns }}$ & $0,48^{\text {ns }}$ & $0,10^{\text {ns }}$ & $1960,47^{\text {ns }}$ \\
C x D & $9,93^{\text {ns }}$ & $2,88^{*}$ & $1,24^{*}$ & $11718,67^{*}$ \\
U x C x D & $12,50^{\text {ns }}$ & $1,30^{\text {ns }}$ & $0,24^{\text {ns }}$ & $3084,78^{\text {ns }}$ \\
Resíduo & 12,50 & 0,81 & 0,15 & 2483,99
\end{tabular}

'Significativo pelo teste F a 5\% de probabilidade; ns: náo significativo

Tabela 4. Equaçóes estimadas para o PCZ em função das doses de gesso para as camadas na condiçáo sem veranico (SV)

\begin{tabular}{cc} 
Tratamento & PCZ \\
\hline Camada A & $P C Z=3,83+0,04 \times R^{2}=0,958^{*}$ \\
Camada B & $P C Z=4,57-0,01 \times R^{2}=0,581^{*}$
\end{tabular}

Significativo pelo teste t a $5 \%$ de probabilidade.

Tabela 5. Equaçôes estimadas para os teores de $\mathrm{Mg}$ em função das doses de gesso para as combinaçóes de umidade e camada

\begin{tabular}{|cc|}
\hline Tratamento & $\mathbf{M g}\left(\mathrm{cmol}_{\mathrm{c}} \mathbf{d m}^{-3}\right)$ \\
\hline SV $0-20 \mathrm{~cm}$ & $0,393-0,036 \times \mathrm{R}^{2}=0,429^{*}$ \\
\hline CV $0-20 \mathrm{~cm}$ & $0,774-0,048 \times \mathrm{R}^{2}=0,612^{*}$ \\
\hline SV $20-40 \mathrm{~cm}$ & $-0,024+0,064 \times \mathrm{R}^{2}=0,702^{*}$ \\
\hline CV $20-40 \mathrm{~cm}$ & $0,131+0,038 \times \mathrm{R}^{2}=49,9^{*}$ \\
\hline
\end{tabular}

Significativo pelo teste t a $5 \%$ de probabilidade.

Tabela 6. Equações estimadas para os teores de Ca e $\mathrm{S}$ em função das doses de gesso para condiçôes de umidade e camadas

$\begin{array}{ccc}\text { Tratamentos } & \mathbf{C a}\left(\mathbf{c m o l}_{\mathrm{c}} \mathbf{~ d m}^{-3}\right) & \left.\mathbf{S ~ ( m g ~ d m} \mathbf{~ d m}^{-3}\right) \\ \text { Camada A } & \mathrm{Ca}=3.06+0.2 \times \mathrm{R}^{2}=0,996^{*} & \mathrm{~S}=103,19^{*} \\ \text { Camada B } & \mathrm{Ca}=2.52+0.14 \mathrm{x} & \mathrm{S}=31.92+9.43 \mathrm{x} \\ & \mathrm{R}^{2}=0,511^{*} & \mathrm{R}^{2}=0,927^{*}\end{array}$

'Significativo pelo teste t a $5 \%$ de probabilidade.

Tabela 7. Comparações de média para os teores de $\mathrm{K}\left(\mathrm{mg} \mathrm{dm}^{-3}\right)$

\begin{tabular}{lcc} 
Tratamento & \multicolumn{2}{c|}{ Condição hídrica } \\
\cline { 2 - 3 } & SV & CV \\
\hline Profundidade A & $11,04 \mathrm{aA}$ & $9,2 \mathrm{aA}$ \\
\hline Profundidade B & $4,25 \mathrm{bB}$ & $7,0 \mathrm{bA}$ \\
\hline
\end{tabular}

SV: sem veranico. CV: com veranico. Médias seguidas de mesma letra minúscula na coluna e mesma letra maiúscula na linha, não diferem pelo teste Tukey (5\%). nesse caso, a adsorção química de sulfato na superfície desses óxidos (WADT, 2000) contribui para a redução nos valores de PCZ. A adsorção deste ânion contrabalança cargas positivas da superfície adsorvente, gerando novos sítios para adsorção de cátions, e com isto reduzir o PCZ.

$\mathrm{O}$ aumento das doses de gesso propiciou a lixiviação de $\mathrm{Mg}$ da camada $\mathrm{A}$, nas duas condiçôes de umidade, reduzindo seu teor nesta camada, demonstrando o efeito significativo das doses (Tabela 5). Contudo, a descida do nutriente na coluna não significou perda total, pois houve acúmulo do Mg na camada B (Figura 2). Parte do acúmulo do $\mathrm{Mg}$ nesta camada foi favorecido pela reduçâo do PCZ à medida que as doses de gesso foram aumentadas, o que significa aumento de CTC que contribuiu para retenção do íon $\mathrm{Mg}^{2+}$; esse fato ameniza, em parte, o efeito negativo do uso de elevadas doses de gesso que é a eventual remoção de nutrientes do solo.

Para o Ca e o $S$, mediante o efeito significativo das doses de gesso, foram ajustados modelos de regressão, conforme abaixo (Tabela 6).

A aplicação de sulfato ao solo, por meio de doses crescentes de gesso, não resultou em aumento dos teores deste $S$ na camada A (Figura 3). Contudo, houve expressivo aumento dos teores de $S$ na camada B (Figura 3). Para a camada $\mathrm{A}$, a presença de maior teor de matéria orgânica, relativamente à camada $\mathrm{B}$, associado à calagem, condicionou aumento da CTC, o que acentua a movimentação do íon $\mathrm{SO}_{4}^{-}$no solo (CAIres et al., 2004). Já na camada $\mathrm{B}$, a fração mineral tem um importante papel no balanço de cargas, expondo, inclusive, cargas positivas (CTA). A adsorção do sulfato a estes sítios reduz sua mobilidade, ocorrendo seu acúmulo, como observado na Figura 3 (WADT, 2000).

As doses crescentes de gesso aumentaram o teor de Ca do solo em ambas as camadas e nas duas condiçóes de umidade (Figura 4). O gesso adicionado à superfície da coluna de solo, no contato com a água, é dissolvido e se

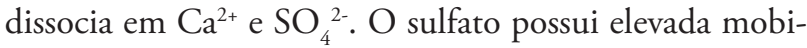
lidade no solo, especialmente na camada superficial, conforme já discutido. Contudo, sua lixiviação no solo não acontece na forma de ânion, mas na forma de compostos formados com outros cátions presentes no solo, cuja afinidade é superior a do $\mathrm{Ca}$, destacando o $\mathrm{K}$ e o $\mathrm{Mg}$ como íons acompanhantes do sulfato (Sobral et al., 2009).

Para o $\mathrm{K}$, não há evidência de perdas devido às doses crescentes de gesso, com base principalmente nos teores desse cátion na camada $\mathrm{B}$, que foram semelhantes àqueles relacionados na tabela 1 , que descrevem o solo na condição inicial do experimento. Contudo, a influência do sulfato na movimentação do $\mathrm{K}^{+}$é bem conhecida e a hipótese de que este ânion tenha sido lixiviado e eliminado da coluna juntamente com o excesso de água, poderá ser aventada. Observa-se que na camada B, com a maior lâmina de água, na condição sem veranico, houve redução nos teores de $\mathrm{K}^{+}$(Tabela 7). 
$\mathrm{Na}$ figura 5, são apresentadas as curvas de retenção de água do solo, para todos os tratamentos. As curvas foram organizadas em quatro grupos, conforme a combinação dos níveis de umidade e o fator camada. Pela combinação destes fatores, tem-se: material do horizonte A sem veranico (SV 0 a $20 \mathrm{~cm}$ ) e com veranico (V 0 a $20 \mathrm{~cm}$ ), e material do horizonte $\mathrm{Bw}$ sem veranico (SV 20 a $40 \mathrm{~cm}$ ) e com veranico (V 20 a $40 \mathrm{~cm}$ ). Não houve influência das doses de gesso na retenção de água. $\mathrm{O}$ uso de amostras deformadas e o tempo de duração do experimento podem negligenciar o efeito do gesso em promover agregação do solo, com provável aumento da porosidade. Contudo, fica evidente que o gesso não tem efeito aparente capaz de alterar a relação da matriz do solo com a água, para as doses estudadas. Desta maneira, os efeitos positivos do gesso na redução do déficit hídrico, relatados na literatura (Sobral et al., 2009), se devem mais ao aumento do volume de solos explorado pela cultura do que ao aumento da capacidade de armazenamento do solo por unidade de volume.

Para o material coletado no Horizonte A, correspondente à camada de 0 a $20 \mathrm{~cm}$ na coluna de solo do experimento, independentemente da presença de veranico nos tratamentos, observa-se decréscimo gradual do conteúdo de água à medida que se aumenta a tensão, em todas as doses de gesso estudadas. Para o material coletado no horizonte $\mathrm{Bw}$, há maior inclinaçáo das curvas na faixa de 1 a $10 \mathrm{kPa}$.

O decréscimo mais gradual do conteúdo de água no material do horizonte $\mathrm{A}$, se deve à maior presença de matéria orgânica, a qual aumenta a capacidade de retenção de água do solo (Celik et al., 2004). Este aumento se faz presente inclusive em amostras deformadas também em razáo da maior quantidade de cargas negativas do solo, aumentando sua capacidade de retenção de água (EMERson et al., 2003).

No solo do horizonte Bw, a mineralogia "oxídica" da fração argila, que promove a formação de microagregados

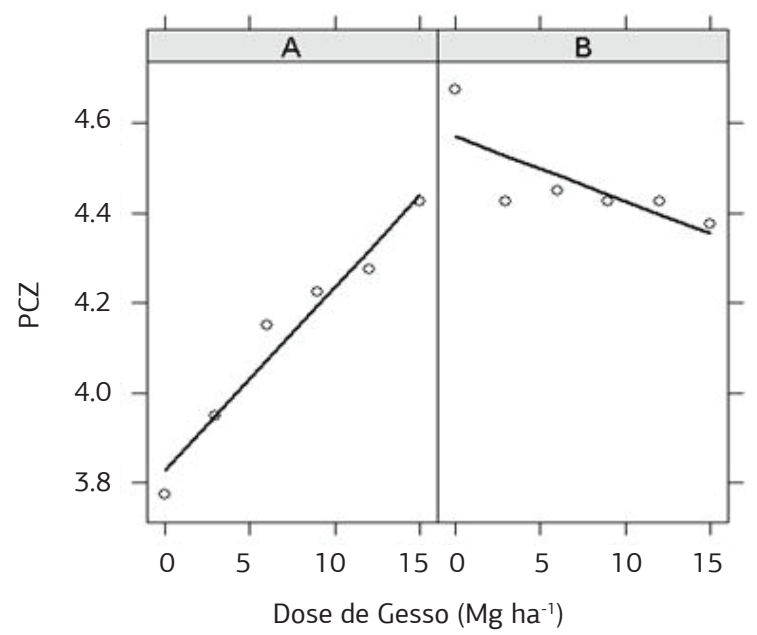

Figura 1. Valor de PCZ nas camadas A $(0-20 \mathrm{~cm})$ e B $(20-40 \mathrm{~cm})$ em função das doses de gesso na condição sem veranico.

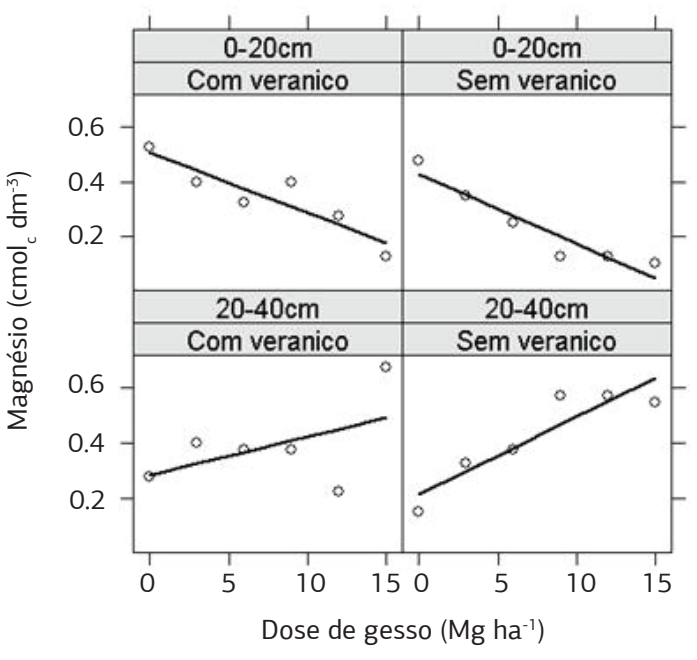

Figura 2. Teores de Mg nas camadas e nas condições com e sem veranico, em função das doses de gesso.

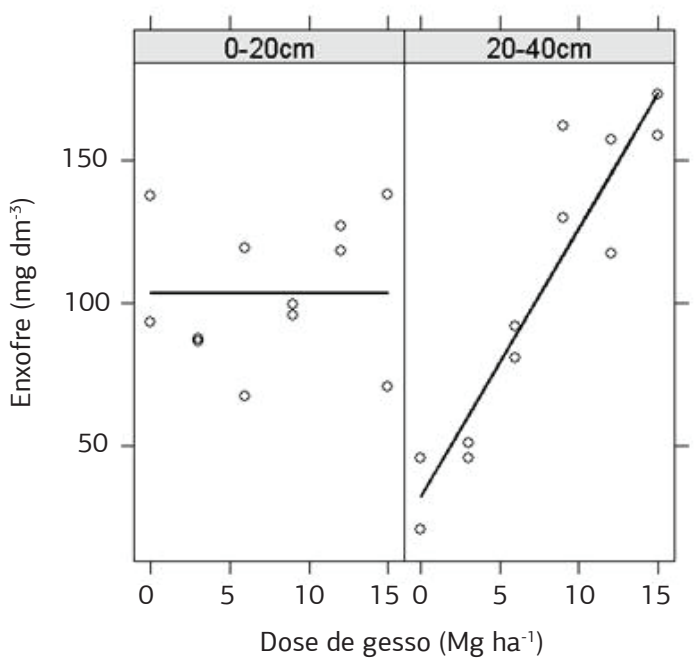

Figura 3. Teores de $\mathrm{S}$ nas camadas em função das doses de gesso.

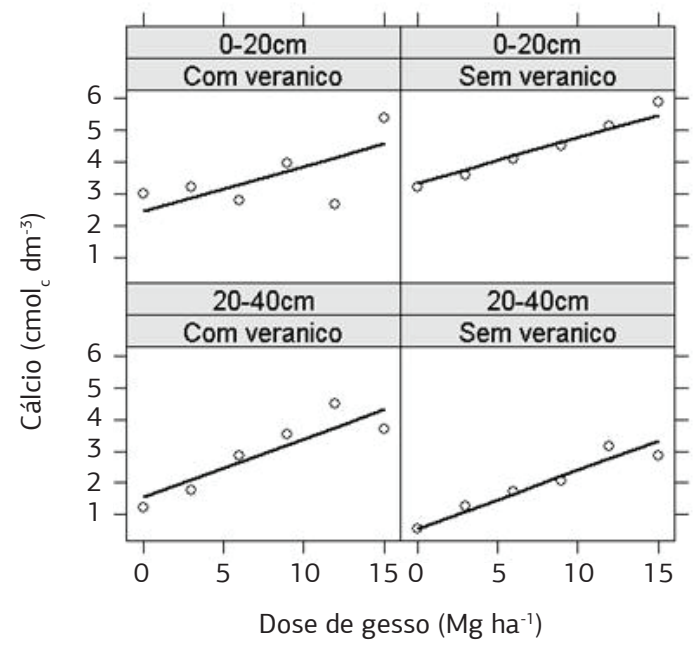

Figura 4. Teores de Ca nas camadas e nas condiçôes com e sem veranico, em funçáo das doses de gesso. 
$-r-r=0$
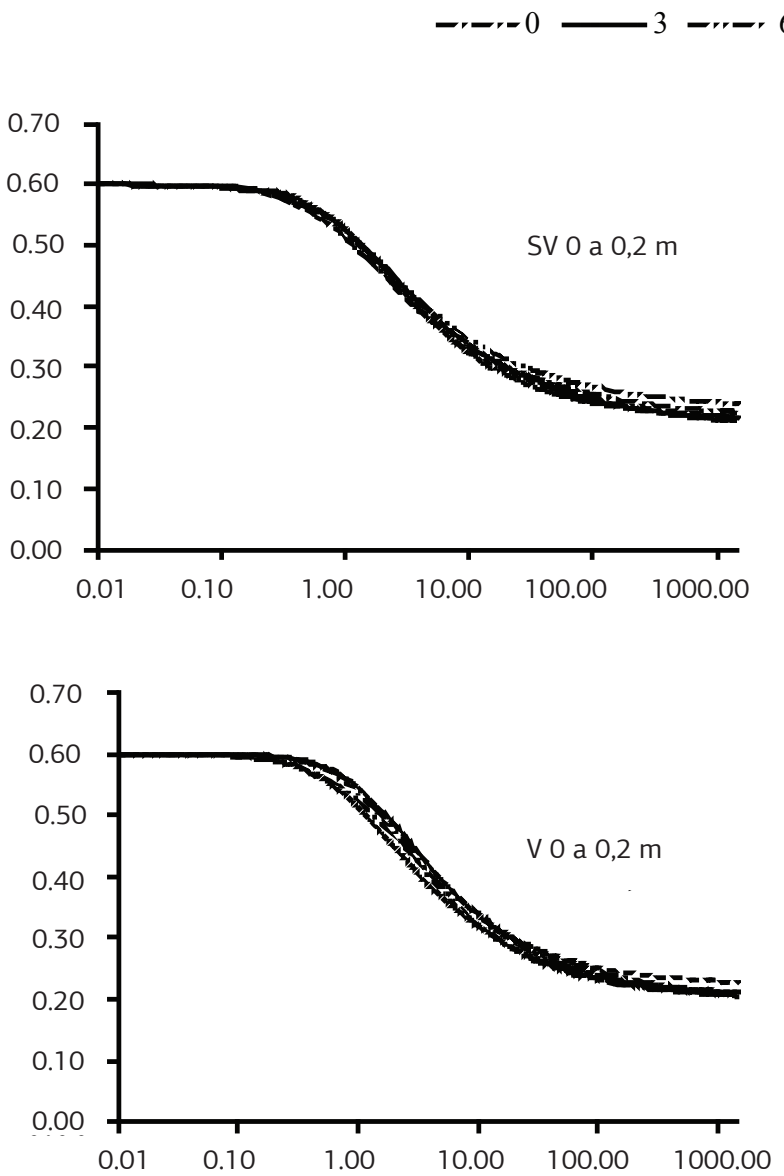
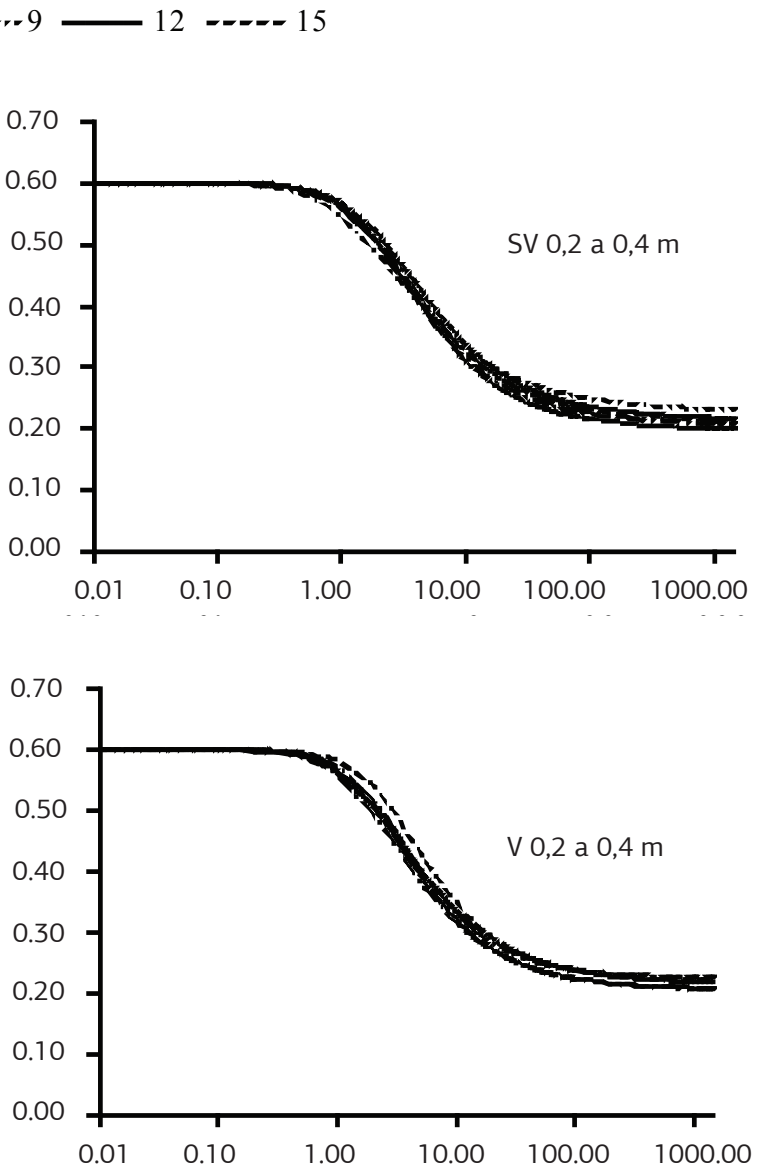

Figura 5. Curvas de retenção de água do solo [(teor de água no solo $(\theta)$ em função do potencial matricial ( $\left.\Psi_{\mathrm{m}}\right)$ ], de um LVdf cultivado com soja em casa de vegetação, com solo coletado nos horizontes A e Bw, sendo horizonte A sem veranico ( $S V 0$ a $20 \mathrm{~cm})$ e com veranico (V 0 a $20 \mathrm{~cm}$ ), e horizonte Bw sem veranico (SV 20 a $40 \mathrm{~cm}$ ) e com veranico (V 20 a $40 \mathrm{~cm}$ ).

arredondados de menos de $1 \mathrm{~mm}$, o que gera duas classes de poros distintas, sendo uma formada por macroporos que perde água facilmente em baixas tensóes e outra de microporos, capaz de reter a água fortemente (FERREIRA et al., 1999). Esse processo acentua o decréscimo da retenção de água, deixando-o abrupto.

\section{CONCLUSÃO}

O gesso agrícola alterou o PCZ do solo e aumentou a lixiviação dos cátions $\mathrm{Mg}^{2+} \mathrm{e} \mathrm{K}$, além do $\mathrm{Ca}^{2+} \mathrm{e}$ do ânion $\mathrm{SO}_{4}^{2-}$. A retenção de água no solo não foi influenciada pelas doses de gesso, sendo influenciada pela matriz do solo de cada horizonte.

\section{AGRADECIMENTOS}

Ao Conselho Nacional de Desenvolvimento Científico e Tecnológico (CNPq), pela bolsa de pesquisa.

\section{REFERÊNCIAS}

BEUTLER, A.N.; CENTURION, J.F.; SOUZA, Z.M.; ANDRIOLI, I.; ROQUE, C.G. Retençấo de água em dois tipos de latossolos sob diferentes usos. Revista Brasileira de Ciência do Solo, v.26, p.829-834, 2002.

CAIRES, E.F.; BLUM, J.; BARTH, G.; GARBUIO, F.J.; KUSMAN, M.T. Alteraçóes químicas do solo e resposta da soja ao calcário e gesso aplicados na implantação do sistema plantio direto. Revista Brasileira de Ciência do Solo, v.27, p.275-286, 2003.

CAIRES, E.F.; KUSMAN, M.T.; BARTH, G.; GARBUIO, F.J.; PADILHA, J.M. Alterações químicas do solo e resposta do milho à calagem e aplicação de gesso. Revista Brasileira de Ciência do Solo, v.28, p.125-136, 2004.

CELIK, I.; ORTAS, I; KILIC, S. Effects of compost, mycorrhiza, manure and fertilizer on some physical properties of a Chromoxerert soil. Soil and Tillage Research, v.78, p.59-67, 2004.

CORINGA, E.A.O.; WEBER, O.L.S. Ponto de efeito salino nulo de Latossolos da microbacia Chico Nunes, Mato Grosso. Revista Brasileira de Ciência do Solo, v.32, p. 441-448, 2008. 
DONTSOVA, K.M.; NORTON, L. D. Clay dispersion, infiltration and erosion as influenced by exchangeable $\mathrm{Ca}$ and $\mathrm{Mg}$. Soil Science Society of America Journal, v.167, p.184-193, 2002.

DOURADO NETO, D.; NIELSEN, D.R.; HOPMANS, J.W.; REICHARDT, K.; BACCHI, O.O.S. Software to model soil water retention curves (SWRC, version 2.0). Scientia Agricola, v.57, p.191-192, 2000.

EMPRESA BRASILEIRA DE PESQUISA AGROPECUÁRIA EMBRAPA. Centro Nacional de Pesquisas de Solos. Manual de métodos de análises de solo. 2.ed. Brasília: Embrapa Produção de Informação, 1997. 212p.

EMPRESA BRASILEIRA DE PESQUISA AGROPECUÁRIA - EMBRAPA. Centro Nacional de Pesquisa de Solos. Sistema brasileiro de classificação de solos. 2.ed. Brasília: Embrapa Produção de Informação, 2006. 306p.

EMERSON, W.W.; McGARRY, D. Organic carbon and soil porosity. Australian Journal of Soil Research, v.41, p.107-118, 2003.

FARIA, C.M.B.; COSTA, N.D.; FARIA, A.F. Ação de calcário e gesso sobre características químicas do solo e na produtividade e qualidade do tomate e meláo. Horticultura Brasileira, v.21, p.615-619, 2003.

FAVARETTO, N.; NORTON, L.D.; JOERN, B.C.; BROUDER, S.M. Gypsum amendment and exchangeable calcium and magnesium affecting phosphorus and nitrogen in runoff. Soil Science Society of American Journal, v.70, p.1788-1796, 2006.

FERREIRA, M.M.; FERNANDES, B.; CURI, N. Mineralogia da fração argila e estrutura de Latossolos da região sudeste do Brasil. Revista Brasileira de Ciência do Solo, v.23, p.507-514, 1999.

FONTES, M.P.F.; CAMARGO, O.A.; SPOSITO, G. Eletroquímica das partículas coloidais e sua relação com a mineralogia de solos altamente intemperizados. Scientia Agricola, v.58, p.627-646, 2001.
MCBRIDE, M.C. Retention of $\mathrm{Cu}^{2+}, \mathrm{Ca}^{2+}, \mathrm{Mg}^{2+}$, and $\mathrm{Mn}^{2+}$ by amorphous alumina. Soil Science Society of America Journal, v.42, p.27-31, 1978.

NOVAIS, R.F; NEVES, J.C.L.; BARROS, N. F. Ensaio em ambiente controlado. In: OLIVEIRA, A.J.; GARRIDO, W.E.; ARAÚJO, J.D.; LOURENÇO, S. (Coord.). Métodos de pesquisa em fertilidade do solo. Brasília: Embrapa-SEA, 1991. p.189-253.

OLIVEIRA, I.P.; COSTA, K.A.P; FAQUIN, V.; MACIEL, G.A.; NEVES, B.P.; MACHADO, E.L. Efeitos de fontes de cálcio no desenvolvimento de gramíneas solteiras e consorciadas. Ciência e Agrotecnologia, v.33, p.592-598, 2009.

RAIJ, B. van. Determinação do ponto de carga zero em solos. Bragantia, v.32, p.337-347, 1973.

RDCT - R DEVELOPMENT CORE TEAM. R: A Language and Environment Statistical Computing. Vienna: R Foundation for Statistical Computing, 2009.

SOBRAL, L.F.; CINTRA, F.L.D.; SMYTH, J.T. Lime and gypsum to improve root depth of orange crop in an Ultisol of the Coastal Tablelands. Revista Brasileira de Engenharia Agrícola e Ambiental. v.13, p.836-839, 2009.

VAN GENUCHTEN, M.T. A closed-form equation for predicting the hydraulic conductivity of unsaturated soils. Soil Science Society of America Journal, v.44, p.892-898, 1980.

WADT, P.G.S. Alterações eletroquímicas de um Latossolo Vermelho-Amarelo tratado com carbonato e sulfato de cálcio. Scientia Agricola, v.57, p.519-524, 2000.

ZAMBROSI, F.C.B.; ALLEONI, L.R.F.; CAIRES, E.F. Aplicação de gesso agrícola e especiação iônica da soluçáo de um Latossolo sob sistema plantio direto. Ciência Rural, v.37, p.110-117, 2007. 